\title{
MOVIMENTO HIGIENISTA E ALTERAÇÕES DO ESPAÇO URBANO NA CIDADE DA PARAHYBA (1854-1912)
}

the Movement Hygienist and changes of the urban space in Cidade da Parahyba (1854-1912)

\author{
Nirvana Lígia Albino Rafael de Sá * \\ Doralice Sátyro Maia **
}

\begin{abstract}
Resumo
Esta pesquisa foi realizada a partir da análise documental de fontes primárias encontradas em arquivos históricos. A partir deste exame, investigamos de que forma a Cidade da Parahyba foi adequada ao ideário higienista, e até que ponto tal ideário foi utilizado enquanto justificativa para as transformações que ocorreram neste espaço urbano, no período situado entre os anos de 1854 a 1912. O principal objetivo foi o de perceber a repercussão e os efeitos do Movimento Higienista na Cidade da Parahyba, especialmente no que diz respeito às alterações urbanas aí ocorridas. Justificamos o recorte temporal estabelecido neste trabalho, por representar, respectivamente, a data de construção do primeiro cemitério público da capital paraibana e, o momento da implantação do primeiro serviço de abastecimento de água na cidade, o qual apesar de apresentar limitacões, atingindo apenas seis ruas da área central, representa um equipamento importante no tratamento da cidade e na busca por tornar este espaço higiênico e salubre. Além destes equipamentos, que se tornaram pontos centrais da análise, procuramos demonstrar algumas outras alterações que ocorreram na Cidade da Parahyba sob os preceitos higiênicos durante o recorte temporal estabelecido, tais como a criação de hospitais e asilos de mendicidade; criação de uma série de posturas e normas que versavam sobre o espaço da cidade e que tinham o intuito de adequar não só seu espaço físico, como também a população que ai habitava aos preceitos higiênicos e as normas de salubridade e embelezamento impostas por tal movimento.

Palavras-chave: Higienismo, Salubridade, Espaço Urbano, Cidade.

Abstract

This research was carried out from the documentary analysis of primary sources found at local and nationa archives. We investigate how the City was adapted Parahyba hygienist ideas and to what extent this ideology was used as justification for the changes that occur in urban space in the period between the years 1854 to 1912. The main objective was to analyze the impact and effects of the Hygienist Movement in the City of Parahyba, especially on the changes occurring there. Justify the time frame established in this work to represent respectively the date of construction of the first public cemetery in the capital of Paraiba and the time of deployment of the first service of water supply in the city. Initially the water reaches just six streets from the downtown area, but represents an important equipment in the search for making this space hygienic and sanitary. In addition to these services attempt to demonstrate some other changes that occurred in the City of Parahyba from Hygienist Movement.
\end{abstract}

Key words: Historical Geography, Hygienism, Salubrity, Urban Space, City.

\begin{abstract}
Resumen
Esta investigación se llevó a cabo a partir del análisis documental de fuentes primarias que se encuentran en archivos locales y nacionales. Se investiga cómo la ciudad se ha adaptado las ideas Paraíba higienista, y en qué medida esta ideología fue utilizada como justificación para que los cambios que se producen en el espacio urbano, en el período comprendido entre los años 1854 a 1912. El objetivo principal fue analizar el impacto y los efectos del movimiento en la ciudad de Paraíba higienista, especialmente con respecto a los cambios que ocurren allí. Justificar el momento elegido establecidas en el presente trabajo, para representar, respectivamente, la fecha de construcción del primer cementerio público en la capital de Paraíba y el momento de la implementación del primer servicio de abastecimiento de agua en la ciudad, que a pesar de tener limitado, llegando a sólo seis calles el área central, representa un instrumento importante en el tratamiento de la ciudad y de la búsqueda por hacer de este espacio higiénico-sanitarias. Además de los equipos que tratan de demostrar algunos otros cambios que se produjeron en la ciudad de Paraíba bajo los preceptos de la higiene.
\end{abstract}

Palabras-clave: Geografía Histórica, Higienismo, Salubridad, Espacio Urbano, Ciudad.

(*) Doutoranda em Planejamento Urbano e Regional pelo Instituto de Pesquisa e Planejamento Urbano e Regional da Universidade Federal do Rio de Janeiro - Cidade Universitária, CEP: 58059-900 - Joao Pessoa (PB), Brasil, Tel./Fax. (+55 83$) 32167595 /$ 32167750 - nirvanadesa@gmail.com

(**) Bolsista Produtividade CNPq e Prof ${ }^{a}$. Dra . do Programa de Pós-Graduação em Geografia da Universidade Federal da Paraíba - Cidade Universitária, CEP: 58059-900 - Joao Pessoa (PB), Brasil, Tel./Fax. (+55 83) 32167595 / 32167750 - doralicemaia@ hotmail.com 


\section{INTRODUÇÃOO}

Relacionado a momentos e contextos históricos diferentes, a cidade ora estudada recebeu várias denominações, as quais se referem ao período econômico, político e ideológico vivenciado na ocasião. No recorte temporal analisado, entre finais do século XIX e início do século XX, a Cidade da Parahyba, antes denominada Cidade de Nossa Senhora das Neves, ou ainda Frederica; e Filipéia de Nossa Senhora das Neves era marcada pela singeleza e por uma vida urbana de pouca intensidade, bem como por uma parca expressividade urbana.

De acordo com Jardim (1910) a Cidade da Parahyba, assim como muitas outras de colonização portuguesa, apresentava, em conseqüência do relevo acidentado na qual se assentava, duas porções diferenciadas, então denominadas de 'Cidade Alta' e 'Cidade Baixa'. A denominada Cidade Alta abrigava neste período, os prédios administrativos e religiosos, graças ao seu relevo, o qual lhe dá maior destaque e visibilidade. Este era, portanto, o local escolhido para o assentamento dessas instituições que aí se colocavam a fim de demonstrar seu poder. Já a Cidade Baixa, ou Varadouro, encontra-se situada exatamente na área da cidade às margens do Rio Sanhaúa, ou melhor, na planície que se situa entre o rio e o tabuleiro, local onde foi construído o porto e a casa de alfândega. A Cidade Baixa era, portanto, representada por um misto de área residencial e comercial, que abrigava os principais estabelecimentos comerciais e as residências de alguns comerciantes, além do porto, citado anteriormente.

Como explica Sales e Maia (2003) “o contraste entre essas duas áreas da cidade não se dava apenas pela sua topografia, prédios e outros tipos de edificações, mas também pela população que circulava pelas ruas: a classe trabalhadora sempre no Varadouro e a elite sempre presente na Cidade Alta (p. 46)", ou seja, a diferença se dava também nos hábitos e costumes vivenciados pela população que residia e/ou transitava por cada uma destas áreas. Além disso,

[...] os elementos que dão forma à cidade - ruas, casas, praças - revelam toda uma estrutura social nela presente. E é na forma, na materialidade que as relações sociais se tornam visíveis. No entanto, toda a projeção que se realiza nas formas da sociedade na cidade constitui apenas uma parte dela. A cidade irá trazer a imagem do dado momento, ela será construída e reconstruída segundo a vontade, o desejo, o esforço e a reflexão do homem, criando assim símbolos que marcarão época. No entanto, essa construção/ reconstrução ocorre diariamente, ela se faz fruto do cotidiano tornando assim, a cidade uma obra inacabada e eternamente dinâmica (SALES e MAIA, 2003, p. 41).

No início do século XIX, a população da Cidade da Parahyba contabilizava um total de 5.816 habitantes, de acordo com o 'Mapa apresentado pelos Vigários das differentes Freguesias', em 1828 (Arquivo Nacional). A partir do século XIX, observa-se "nas principais cidades brasileiras, grandes mudanças acontecem [...] tais como o aumento demográfico, a institucionalização da propriedade privada, as melhorias de transporte e infra-estrutura urbana como a instalação da iluminação, do abastecimento d'água ou ainda o início da promoção imobiliária" (MAIA, 2008, p. 02). Estes serão, portanto, os principais fatores responsáveis pelas modificações observadas na Cidade da Parahyba tanto em relação à sua morfologia ou à distribuição dos seus habitantes, como aos seus hábitos e costumes.

Embora haja dificuldades em afirmar um quantitativo populacional para a Cidade da Parahyba durante o período analisado, visto a ausência de documentos, partimos do Relatório do Presidente da Província de 1854, o qual mesmo afirmando que "não tem sido possível obter uma estatística completa da população da Província. Os dados que existem [...] são muito imperfeitos, e apenas podem dar uma ideia aproximada da verdade" (p.18), aponta que em 1852, a população da [Província da] Parahyba "não excede a 211.952 almas, sendo 183.479 de pessoas livres e 28.473 de escravos.” Já a população da Cidade da Parahyba, capital da Província, atinge a cifra de 28.000 habitantes em 1869, de acordo com uma comissão de médicos que "sob a presidencia do Inspector 
de Saude Poggi, deviam (sic!) estudar o assunto e propor medidas" (MEDEIROS, 1910, p. 121). A partir da análise do relatório elaborado por esta comissão, pode-se afirmar que a população que contava com 13.000 habitantes em 1869, momento da elaboração do referido relatório, eleva-se a 28.000 em 1911. Embora a população tenha apresentado o acréscimo acima referido, problemas em relação à urbanização e, sobretudo à salubridade atingem o espaço da cidade. Ramalho (1958) explana que as causas de insalubridade, apontadas pelas comissões de higiene e pelos administradores locais continuavam a existir durante anos, mesmo que houvessem sido classificadas como focos de disseminação de doenças e sugeridas sua extinção nos relatórios de saúde pública. Entre estas causas, o autor, cita:

[...] a localização e construção do cemitério publico, o qual ainda hoje está prestando serviços; o despreso em que deixaram os princípios de hygiene na construcção do matadouro público; a falta de asseio das ruas e praças; inconstâncias das estações; a estagnação das águas do [Rio] Jaguaribe, da lagoa e águas salgadas no soppé occidental da cidade. (MEDEIROS, 1910, p. 141)

Os relatórios dos Presidentes da Província e ainda os relatórios referentes às repartições de saúde destacam ainda como causas de insalubridade a ausência de determinados equipamentos urbanos e da atuação do poder público:

[...] pouca limpeza e asseio que se observa nas ruas d'esta Cidade, um grande lamaçal que existe á leste da estrada, que communica a ponte sobre o Rio Sanhauá com a Cidade baixa e o rio Jaguaribe, que costeia a capital pelo lado do leste, cujas águas não dispondo de livre curso, em conseqüência da obstrucção do seu leito, acha-se, por conseguinte, transformado em um extenso pântano, coberto de vegetação aquática; o que concorre poderosamente para a alteração, que se nota n'este importante ramo do serviço público (RPP, 1882, p. 21).

O Presidente da Província no ano de 1879 complementa ainda ao dizer que se fazia necessário para a manutenção da ordem pública da cidade e da saúde de seus habitantes que esses focos de insalubridade fossem extintos "pelas leis da hygiene", o que, no entanto, não ocorria nesta Província "devido sem dúvida, á defficiencia dos seus recursos" (RPP, 1882, p. 21). Em relação à saúde e à salubridade pública na Cidade da Parahyba, vários são os registros que afirmam a deficiência da mesma. Como pode ser observado a partir da análise do trecho do relatório do Presidente da Província em 1882 abaixo transcrito:

em qualquer canto, em todas as ruas e beccos encontra-se montes de lixo, animaes mortos em putrefação, materiaes fecaes, e águas podres estagnadas: de sorte que, se todos esses focos pestilenciaes não fossem modificados em sua acção destruidora pela vegetação, que cobre em grande parte o solo, e pelo clima reconhecidamente salubre, estaríamos sempre sob a pressão de frequentes e graves cataclysmas epidêmicos. (RPP, 1882. p. 02)

Essas eram as principais causas apontadas nos ditos relatórios para a ocorrência das epidemias que assolavam a Cidade da Parahyba ao longo dos anos de 1854 e 1912. É importante, pois, estudar e analisar as medidas que foram tomadas e/ou recomendadas para o seu combate. Estas, por sua vez, promoveram ou reivindicaram alterações no espaço urbano da Cidade da Parahyba.

\section{O IDEÁRIO HIGIÊNICO E A CIDADE DA PARAHYBA}

Partimos do entendimento de que, desde o século XVIII, e mais especificamente a partir do século XIX algumas mudanças foram verificadas em relação à distribuição e concentração dos habitantes nos território das cidades. Na Inglaterra, por exemplo, estas modificações foram ocasionadas principalmente pela denominada primeira fase da Revolução Industrial. O crescente desenvolvimento da indústria influenciou um acréscimo na concentração e na densidade dos habitantes nas cidades, 
e fez com que esses locais se tornassem verdadeiros centros de aglomerados humanos em rápido crescimento. Junto a esse acréscimo populacional verifica-se a ocorrência de muitas epidemias, que assolavam e dizimavam a população, pois, com o adensamento, a transmissão e o contágio das doenças se dava com maior rapidez.

Todo esse adensamento populacional gera algumas exigências decorrentes tanto do déficit e da má qualidade das habitações; como da intensificação e proliferação de doenças entre os habitantes. Acreditava-se que a grande concentração de pessoas em espaços não suficientes para a circulação do ar seria a grande causa da ocorrência de epidemias. A denominada 'Teoria dos Miasmas', defendia que as doenças eram transmitidas pelos ares de uma atmosfera contaminada por estarem concentradas nos ambientes, principalmente naqueles habitados pela população de menor poder aquisitivo. Por conseguinte, havia um fortalecimento do preconceito social que justificava as intervenções autoritárias e o afastamento da considerada população "perigosa" dos lugares habitados pela "boa gente".

As concepções sobre a origem e disseminação de doenças a partir do ambiente físico levaram à necessidade de uma gestão higiênica da habitação e dos espaços para que fosse evitada a ocorrência das epidemias. A partir desse entendimento, os recursos para cura e prevenção, em sua maioria resumiam-se ao saneamento. A higiene passa então a ser considerada como algo imprescindível, ou seja, uma das formas principais de evitar infecções, fazendo com que as cidades se tornassem 'alvo' no sentido de receber equipamentos urbanos que favorecessem a higienização, como a instalação de serviços de abastecimento de água; de saneamento; o controle sobre a construção de habitações, construção de cemitérios públicos, e matadouros, entre outros. A higiene, portanto, é considerada como "a parte da medicina administractiva, que tem por fim conservar a saúde e a vida, aperfeiçoar nossas faculdades, fasendo-nos gosar e usar de huma maneira conveniente de tudo que nos cerca, e evitar o perigo ligados ao abuzo." (Correspondências com o Ministério do Império. 15 de outubro de 1863).

Neste intento, Boarini (2003) demonstra que, sobretudo a partir de meados do século XIX, a ciência através do saber médico, passa a interferir sobre o espaço habitado. Os médicos veiculavam por meio de jornais e revistas da época que os males epidêmicos se proliferavam devido aos maus hábitos da população, e que era preciso difundir entre os habitantes da cidade condutas condizentes com os preceitos científicos. Seria através desta mudança de costumes da população que as cidades tomariam ares de urbe moderna, conforme podemos observar no documento que se segue.

O Movimento que incita todas as cidades a submetter-se as exigências de hygiene moderna, sob pressão enérgica da opinião publica, é irresistível. Torna-se felizmente, de mais a mais temerário de evital-o [...] A morada pode ser comparada a um organismo vivo, si as leis que regem a natureza que nos envolve e que vive de ar, de luz e d'água são respeitadas. As casas insalubres, as casas de taipas, as cobertas de folhagens, receptáculo de insetos e outros, sacrificam esses elementos.

Tal concepção entendia que, quanto mais a cidade e sua densidade crescem, maiores os problemas em relação à estética, à insalubridade, aos resíduos sólidos e líquidos, por isso as contaminações que daí surgem são transmitidas dos bairros populares (vistos como responsáveis pela origem e contaminação de doenças) para os burgueses e aristocráticos, ou seja, para os bairros centrais onde habitava a elite dominante, levando a criação e ao surgimento de inúmeros regulamentos, determinações, posturas e decretos que alterassem a maneira como se daria o tratamento sobre o espaço urbano.

A partir da análise documental, constatamos várias modificações na Cidade da Parahyba, que são determinadas tanto pelas normatizações advindas da Capital do Império, ou posteriormente da República; como aquelas propostas pela Câmara Municipal da cidade, tais como: construção de calçamento e passeios em frente às casas da Rua Conde d'Eu; os passeios da Rua São Francisco em 1874; o calçamento da Rua São Frei Pedro Gonçalves e da Estrada da Gamelleira em 1889. Essas intervenções, somadas a inúmeras outras, exemplificam bem a tentativa e as atuações voltadas para o embelezamento e a higienização da cidade. 
Para Andrade (2005) foi principalmente durante o século XIX que surgiu a necessidade de alinhar as ruas, "contrapondo-se as ruas sinuosas, feitas sem obediência às normas e seguindo o relevo" (p. 74). Neste momento, foram formuladas, na Cidade da Parahyba, as chamadas Posturas Municipais, documentos que contêm normas especificamente urbanas e são elaborados pelas Câmaras Municipais. Ao analisar estas posturas percebemos a pretensão por parte dos administradores locais em acompanhar as tendências de modernidade e a preocupação com a boa aparência da cidade que eram trazidas da Europa para a Capital do Império e desta para as demais capitais das províncias, mesmo com suas diferenças de graus e intensidade.

Note-se que as determinações expressas nos documentos analisados confirmam o ideário e os objetivos por parte do poder municipal em adequar a Cidade da Parahyba aos padrões de higiene e salubridade, precisando para isto modificar o espaço físico da cidade e os hábitos da população mesmo que por força punitiva. Como podemos aqui demonstrar, o cumprimento das determinações higiênicas fazia com que se afastasse da área central da cidade não só os hospitais _ como o da Santa Casa da Misericórdia que deixa a Rua Direita e passa a situar-se em área distante, denominada Cruz do Peixe _ mas também as habitações da população pobre. Assim como os hospitais e os doentes são afastados da cidade, os mortos também passam a ocupar outro espaço: os cemitérios.

O discurso da higiene insere-se, portanto, nesta nova forma de controle social e de exercício do poder por parte da elite sob a população em geral, população esta que, em sua maioria não tinha condições de acompanhar tal discurso. Desta maneira, não apenas o lugar, mas os valores "atribuídos ao modelo de urbanização, representado pelo modelo de cidade moderna, higiênica, saudável, contribuíram para o esquadrinhamento de homens e mulheres" (CAMPOS, 2004, p.14). Ideias estas que geram exclusão e segregação na cidade ora analisada, não apenas observadas a partir da disposição dos equipamentos urbanos instalados, como também nas próprias habitações (tipos de construção e lugares construídos). A escolha dos lugares onde seriam ofertados e/ou implementados alguns equipamentos urbanos, bem como a não oferta dos mesmos, relacionava-se também ao conhecimento científico da época sobre o contágio e a transmissão de doenças, já que cabia aos engenheiros sanitários e aos médicos responsáveis pela administração pública a escolha do lugar e a execução da planta dos equipamentos urbanos a ser instalados na cidade, ou ainda a abertura de novas ruas e até mesmo a disposição das habitações.

O conhecimento científico e a forma como se planejava a cidade são modificados ao passo que outras teorias médicas são descobertas. Por muitos anos acreditou-se que as doenças eram propagadas através do ar e que era a partir dos lugares e da má gestão dos espaços urbanos que se daria a ocorrência de epidemias. A Teoria dos Miasmas irá, portanto, fundamentar a criação das primeiras leis higiênicas e sanitárias no mundo, bem como a 'Comissão dos Pobres' que atuava no ano de 1832, na cidade de Londres; a Lei dos Pobres, de 1834, na mesma localidade; ou ainda o estudo, realizado em 1845 que culmina com a construção de um relatório da Comissão Real de Londres sobre o estado das grandes cidades e dos distritos populosos, no qual se fazem recomendações para impor às habitações condições higiênicas mínimas a fim de melhorar e alargar ruas; abrir parques públicos e instalar alguns equipamentos urbanos considerados necessários aos bons hábitos higiênicos da população.

\section{AS EPIDEMIAS E AS DETERMINAÇÕES HIGIÊNICAS NA CIDADE DA PARAHYBA}

Ao estudar as epidemias, especialmente a epidemia da cólera que assolou a Região Nordeste durante o século XIX, Diniz (2001) explana as teorias médicas que foram sendo formuladas ao longo dos tempos com o objetivo de investigar a ocorrência e transmissão das doenças. Desta forma, o imaginário da doença no século XIX, quando se acreditava nas teorias de contágio e dos miasmas é "alimentado pelo desconhecimento das causas do mal, impotência da medicina, súplicas, preces, desânimo e, sobretudo, medo do contágio" (DINIZ, 2001, p.121). É exatamente este medo do contágio e o desconhecimento das causas das doenças que vai gerar o temor em relação à aproxi- 
mação de outros, ou seja, daqueles considerados doentes ou propensos a adoecer, principalmente os pobres e desempregados, favorecendo desta forma, a exclusão e a segregação na cidade. A respeito da inexistência de conhecimento quanto às causas das doenças, transcrevemos trecho de uma carta escrita pelo então Presidente da Província no ano de 1863, na qual, trata da cólera afirmando ser

[...] inútil discutir seriamente, com os cênicos dados, que temos ate hoje colhido, qual a causa primordial do cholera, attendendo-se que essa moléstia epidêmica tem-se desenvolvido e propagado no espaço de 15 annos através de 3 milhões de legoas quadradas em paizes e regiões diversas, e no meio de condicções hygienicas e clymatericas inteiramente oppostas. O que porem é senão incontestável, ao menos racional, é suppor-se a existência de uma causa especifica provavelmente espalhada na athmosfera, mas que até hoje se não tem dado a Ella uma demonstração plausível e satisfatória (Correspondências com o Ministério do Império. 12 de janeiro de 1863. Arquivo Nacional).

Desta forma, observamos que, eram as características atmosféricas as principais causas identificadas para a ocorrência de determinadas doenças. As condições naturais do lugar, ou seja, o relevo, o clima, a ocorrência de ventos e a incidência de raios solares, seriam considerados os principais fatores causadores das doenças. Entre os fatores que compunham as condições naturais da Cidade da Parahyba são destacados nos documentos analisados os pântanos e as áreas alagadiças, o que em conseqüência, gerou inúmeras solicitações de obras para que os mesmos fossem removidos da área habitada da cidade, a fim de evitar a ocorrência de epidemias.

Em relação às epidemias que assolaram a Cidade da Parahyba durante o período analisado, averiguamos que em 1853, segundo o Presidente da Província, "nenhum mal epidêmico tem accometido esta Capital. A febre amarella, louvado Deos, não tem feito novas victimas, e somente as febres intermitentes que sempre costumam apparecer pela mudança da estação tem-se feito sentir no meio da população" (RPP, 1853, p. 22). No entanto, não demorou muito para que esta cidade fosse atingida pelo mal epidêmico, tal como ocorria nas províncias vizinhas. O Presidente da Província em seu relatório para o ano de 1855 divulga que "a peste das bexigas que em alguns mezes passados tanto perseguia os habitantes desta Capital e de alguns pontos do interior, tem consideravelmente arrefecido" (RPP, 1855, p. 03). E afirma ainda neste mesmo ano que:

[...] com pezar vos annuncio que o estado da saúde publica na Provincia não é lisongeiro: a peste das bexigas tem lavrado com intensidade em alguns pontos d'ella, com especialidade n'esta capital onde tem feito não pequeno numero de victimas, mas quase todas na classe baixa do povo principalmente entre os presos da cadeia, muitos dos quaes não são vaccinados, e vindos do interior aqui permanecem amontoados em espaço relativamente acanhado, onde por consecuencia não se encontrão as condicções de boa hygiene. (RPP, 1855, p. 08)

Essa epidemia levou o Presidente da Província a contratar dois médicos, três estudantes de medicina e um farmacêutico a fim de "facilitar não só medicamentos, como facultativos aos habitantes daquelles lugares, onde taes recursos absolutamente fallecem [...] apesar de exagerado preço, que elles conhecendo a necessidade urgente e únicos no lugar, impoem a seus serviços" (Correspondências com o Ministério do Império. 11 de setembro de 1857. Arquivo Nacional). Ainda no ano de 1855, o Secretário do Governo da Parahyba em comunicação com a Corte Imperial reclama que "sendo mui sensível n'esta Provincia a falta de um médico, a ausência do sobredito Dr. deixa n'ella um vácuo impossível aqui de preencher". (Correspondências com o Ministério do Império. 11 de julho de 1855. Arquivo Nacional) E conclui rogando que o Ministério tenha "a honra" de providenciar a verba necessária para que tal falta seja preenchida, a fim de que seus habitantes sejam "socorridos em suas necessidades pelos benefícios da Medicina, agora principalmente que, segundo me parece, somos ameaçados da terrível epidemia de cholera-morbus" (Correspondências com o Ministério do Império. 11 de julho de 1855. Arquivo Nacional) 
Quanto às epidemias de cólera, podemos dizer que estas foram as que mais incomodaram as autoridades de saúde da Cidade da Parahyba, quanto ao número de pessoas vitimadas a cada surto desta doença, daí a importância por combatê-la, evitando sua ocorrência e disseminação. Esta afirmação poder ser exemplificada ao observarmos:

O cholera-morbus [...] preocupa a Administração Publica, roubou ao Paiz um crescido numero de filhos, e tirou dos cofres da Nação sommas, que deverião ser despendidas com as industrias e a lavoura, que infelismente vão cada dia em definhamento! [...] Todas as questões de hygiene social apresentam duas faces, uma puramente médica, e outra civil: a hygiene publica por tanto tem na administração baseadas nos conhecimentos médicos e outra nos recursos da Nação: observar ou mesmo destrui-las é do domínio da administração medica, empregar os recursos da Nação em bem da salubridade é do domínio da administração civil. (Correspondência com o Ministério do Império. 11 de maio de 1862. Arquivo Nacional)

Em 1856, além da cólera, a peste de bexigas continuava a fazer vítimas, embora houvesse uma diminuição considerável no número de mortos se compararmos com anos anteriores. Diminuição esta atribuída, pelas autoridades, a algumas melhorias nos hábitos higiênicos dos habitantes, mas, principalmente ao serviço de vacinação, o que muitas vezes mostra-se contraditório pois a maioria dos documentos apresenta as dificuldades e reclama a repugnância do povo em relação ao serviço de inoculação da vacina, alguns outros demonstram algum crescimento no número de pessoas vacinadas. Acreditamos que estes últimos ocorrem como estratégia de convencer a população sobre a importância deste serviço.

Em relação à vacinação, vale apontar que desde 1830 a vacinação infantil passa a ser obrigatória. Apesar dessa obrigatoriedade, poucos pais cumpriam com tal determinação, isto por várias razões: o método de inoculação além de lento era bastante doloroso. Em 1844, foi decretada uma nova postura em relação à vacinação infantil. Esta deveria ocorrer entre os 04 meses e 01 ano de idade, sob pena de multa aos pais ou responsáveis, e para garantir maior controle, os adultos não vacinados não poderiam ter emprego público, nem mesmo ingressar em escolas, sejam estas públicas ou privadas.

Vários são os registros e documentos escritos pelas autoridades locais que nos revelam como ocorria o serviço de vacinação na Cidade da Parahyba, ou mesmo, no interior da Província, sendo a maior parte deles reclamações sobre a qualidade do 'pus vacínico', sua quantidade ou mesmo a falta de interesse do povo por submeter-se a tal procedimento. Em relatório, o Presidente da Província reclama sobre o serviço ao dizer que: "infelizmente a vaccina não tem tido da parte da população [...] a acceitação que éra de desejar, e este facto não deixa sem duvida de contribuir para a propagação do mal e de seus terríveis effeitos" (RPP, 1856, p. 19). Neste mesmo ano, o comissário vacinador desta Província solicita uma "remessa de puz vaccinico, de que há por aqui falta absoluta [...] por ocazião do apparecimento da peste das bexigas na Cadêa publica d'esta cidade" (Correspondências com o Ministério do Império. 11 de setembro de 1857. Arquivo Nacional ).

Embora muitos obstáculos sejam expressos, em 1875, o Inspetor de Saúde Pública da Cidade da Parahyba expõe que, apesar de todas as dificuldades para o bom funcionamento do serviço de vacinação da Cidade da Parahyba, como por exemplo, "a repugnância de uns, e os preconceitos de outros", foram vacinados 1354 pessoas durante este ano, concorrendo, ainda segundo o mesmo, com o bom estado sanitário da Província e principalmente com uma redução no número de mortos. Afirma neste sentido que "raríssimo é o caso de varíola em algum individuo n'esta capital, devido a estar a maior parte da população vaccinada, ao passo que são constantemente affectadas todas quantas vem ao interior da Provincia, que se descuidão de procurar a vaccina" (Correspondência com o Ministério do Império. 11 de dezembro de 1874. Arquivo Nacional).

Esses e outros dados divulgados na dita correspondência, nos indicam que em cerca de três semanas, houve, em março de 1856, mais de 400 vítimas na Cidade da Parahyba, número acrescido 
para 1.110 mortos no mês de abril, momento em que se iniciou um processo de declínio no número de mortes, ou seja, quando a epidemia passou a ser controlada.

A fim de justificar a pouca eficácia das ações do governo e da ciência no que concerne a prevenção da ocorrência de doenças, em seu relato, Irineo Pinto afirma ainda que: "a intensidade delle tornava nulla qualquer medida adoptada pelas autoridades sanitárias [...] pela falta de conhecimento e preparo dos meios para repellil-o, apellando as populações quasi que exclusivamente para o ceo, onde estava a ultima esperança de salvação" (PINTO, 1910, p. 118). As causas apontadas para a ocorrência desta epidemia são várias, conforme demonstramos anteriormente. No entanto, podemos perceber que vários eram os autores que afirmavam ser esta de caráter natural, transmitida pelo ar, como afirmava a Teoria dos Miasmas. Pinto (1910), por exemplo, explana que: "o transbordar dos rios, inundando grandemente as suas margens, trouxe a decomposição de detrictos orgânicos alli acumulados, sendo isto, segundo pensam, de fevereiro a primeiro de abril, somente um més e cinco dias, foi preciso para uma verdadeira hecatombe social." (Idem, p. 126). Além destas, figuravam entre as causas apontadas para a ocorrência e determinação de doenças e das epidemias, uma

má alimentação plástica, assim como respiratória [...] o desprezo sobre tudo que directamente concorre para viciação do ar que respiramos [...] as más porcas e lamacentas e sujas, os monturos a cada canto, os esterquilínios em quasi todos os bêcos e ladeiras, as aguas estagnadas e pobres, a decomposição e suas exhalações mephiticas miasmáticas a influir alta e poderosamente sobre a salubridade publica. (Correspondência com o Ministério do Império. 15 de outubro de 1863).

Fazia-se necessário, portanto extinguir estes focos de infecção, determinando medidas higiênicas a serem tomadas tanto em relação ao espaço urbano como à população. Para o tratamento da epidemia da cólera, muitas eram as medidas determinadas pelo governo, pelos médicos e engenheiros, principalmente as que diziam respeito à extinção dos problemas citados anteriormente. Contudo, o que podemos observar, a partir da análise documental, é que havia uma série de dificuldades para que a Cidade da Parahyba fosse dotada dos meios necessários à prevenção. Reclama-se, entre outras coisas, do "numero redusido de facultativos, insufficiente mesmo em tempos ordinários, a falta de hospitaes onde possam ser tratados as pessoas pobres e desvalidas entre as quaes são maiores os estragos: todas estas considerações afflictivas tem convertido aquelle receio em quase terror" (PINTO, 1910, p.121). Em relação aos pobres, que muitas vezes eram classificados como responsáveis pelo surgimento e pela transmissão de doenças, muitas eram as medidas tomadas para seu disciplinamento, exemplo disso, é o documento no qual o Presidente da Província da Parahyba na época expõe que

A gente mais desvalida, como succede quase sempre em todas as epidemias, foi também aquella que mais soffrêo, sendo a rasão disso fácil de achar-se na apreciação das condicções proprias da pobresa e de suas necessidades, no abuso constante que tal gente comete em todos os sentidos, principalmente quanto ao uso de alimentação (Correspondência com o Ministério do Império. 17 de janeiro de 1868. Arquivo Nacional).

Esses foram, portanto, os fenômenos apontados como causa dos dois principais surtos de cólera que assolaram a Cidade da Parahyba. O primeiro grande surto epidêmico ocorreu entre os anos de 1855 e 1856 "apesar das enfermarias e boticas que foram estabelecidas para a pobresa, onde apesar da promptidão e da caridade, com que eram soccorridos e affectados, elevou-se a cifra obituária a 1.518 mortos" (PINTO, 1910, p. 128).

De acordo com Oliveira (1958), essa epidemia penetrou a Parahyba, vinda da província vizinha, Pernambuco, através da cidade paraibana de Pedras de Fogo, causando nesta cidade, cerca de 3.840 mortos. Já o segundo surto, ocorrido a partir do ano de 1862 apesar de ter gerado vítimas nas províncias de Pernambuco, Paraíba e Rio Grande do Norte, não foi tão violento, em número de mortos quanto o primeiro, isso porque, segundo o referido autor "agora concorriam, ao par de 
taxa embora precária de imunizados pela epidemia anterior, possivelmente experiência e recursos maiores para uma defesa mais proveitosa." (OLIVEIRA, 1958, p. 20 e 21).

O segundo surto de cólera, ocorrido na década de 1860 na Cidade da Parahyba promoveu algumas alterações na cidade, como por exemplo, o improviso de enfermarias. Neste momento, uma enfermaria foi construída no Convento de São Bento para tratamento dos acometidos desta doença durante o período de surto. Além de outras medidas, como a tentativa de realizar uma educação higiênica entre a população foram tomadas. Esta tinha o intuito de favorecer a prevenção a esta doença, de acordo com os conhecimentos da época. É o que relata Oliveira (1958) ao explanar que "também a imprensa quis entrar com a sua cota-parte nessa generosa obra de solidariedade humana, tomando a si, entre outras incumbências, a de ministrar avisos, instruções, conselhos sobre os cuidados que a oeste reinante e até como se proceder a medicação dos coléricos" (p. 21). Os avisos noticiados pela imprensa tinham o intuito, portanto, de divulgar entre a população, os preceitos medicamentosos e a prevenção para determinada doença.

Os surtos epidêmicos de cólera que assolaram a cidade levaram a que os médicos e medicamentos que eram destinados a esta capital não fossem capazes de tratar o grande número de infectados pela cólera, já que, em um único dia, segundo dados fornecidos na Revista do Instituto Histórico e Geográfico da Paraíba, morreram 49 pessoas, mesmo “em uma população tão pequena". O autor afirma ainda que "de certo, a Província, quiçá a capital, ficaria despovoada." (PINTO, 1910, p. 129).

Todavia, não seria apenas a cólera que faria vítimas na Cidade da Parahyba, outras doenças foram identificadas como causas de mortes. Neste sentido, o Inspetor de Saúde Pública na Província, no ano de 1875 mostra em seu relatório a existência de febre amarela e de varíola, além de outras "entidades mórbidas que ordinariamente aparecem em conseqüência de causas naturaes e accidentaes que estão todos sujeitos" (Correspondência com o Ministério do Império. 30 de janeiro de 1875. Arquivo Nacional). Não obstante esses dados, o mesmo Inspetor afirma ser difícil escrever acerca da saúde na/da Província

[...] para que Ella fosse minuciosa, e completa e tivesse a importância e utilidade, reclamadas pelo bem publico, seria preciso que fosse baseada em dados scientificos, e informações regularmente ministradas por profissionaes encarregados de tão útil tarefa. Mas infelismente assim não succede, em virtude da irregular e defeictuoza organização deste importante ramo de administração, que cada dia reclama promptas providencias dos altos poderes do Estado (Correspondência com o Ministério do Império. 30 de janeiro de 1875. Arquivo Nacional).

Contudo, devido à necessidade de relatar o estado sanitário em que se achava a Província, semestralmente o Inspetor de Saúde tinha a incumbência de enviar relatórios acerca do tema para o Ministério do Império. Dados estes que se encontram catalogados no Arquivo Nacional, e dos quais, juntamente com outras fontes documentais, nos utilizamos para a construção do referido trabalho.

A partir do exposto, podemos inferir ainda que em 1878, a epidemia de febre amarela grassava na cidade e, sobretudo nas tripulações advindas de outras localidades e embarcadas no porto. Conforme podemos perceber nos documentos oficiais e nas correspondências emitidas pelo então Presidente da Província "a febre amarella, que por vezes tem manifestado e propagado nas tripolações dos navios estrangeiros, que demandam este porto no tempo da safra e na estação calmosa, este anno apareceo" (RPP, 1878, p.41). As causas dessa enfermidade eram o "envenenamento miasmático produzido pelas emanações, que se desprendem dos pântanos, dos esterquilineos, do cemitério, do matadouro e de outros focos de infecção, sob cuja inffluencia vive a população" (MEDEIROS, 1913, p. 122). Este trecho de documento, extraído da Revista do Instituto Histórico e Geográfico da Paraíba é complementado por outro intitulado: 'A Nossa Hygiene: Considerações Geraes', de autoria de Flávio Maroja, publicado na mesma revista, o que indica a importância deste tema para a população da cidade à época, já que muitos são as divulgações em jornais, revistas, e ainda em documentos oficiais, tais como posturas e decretos que versavam sobre o tema. Este autor escreve, 
ao complementar o que anteriormente escrevera Coriolano de Medeiros que "por onde quer que se comece o estudo das diversas causas, productores umas, e aggravantes outras, de má hygiene da nossa capital, ver-se-a no seu termino, que são innumeras essas causas, cada qual mais carente de prompto e efficaz remedio, todas merecedoras de um remodelamento accorde ás exigências da hygiene moderna." (MAROJA, 1913, p. 431)

Em 1882, o Presidente da Província afirma que, em relação aos riscos epidêmicos, as febres eram as que mais acometiam a população desta cidade, estas eram "em geral benignas e cedendo a um tratamento regular, muitas vezes revestiam-se de symptomas typhicos, e com perturbações taes, que zombavam de todos os esforços da medicina. Não foram muitas as suas victimas, no entanto succumbiram algumas sob sua acção." (RPP, 1882, p. 04). E acrescenta ainda que essas febres que ocorreram na cidade neste ano são decorrentes "de uma entoxicação produzida por emanações deletérias, que se desprendem dos pântanos, esterquilinios existentes no centro da Cidade, do Cemitério, do matadouro e de outros locos de infecção" (Id. Ibd.), os quais deveriam, como vimos, ser regulados e controlados a partir de medidas sanitárias.

Em comunicação com o Ministério do Império, o então Presidente da Província afirma, no ano de 1860, que "a epocha das enchentes dos rios na estação das chuvas assignala o apparecimento de febres e outras enfermidades em consecuencia da insalubridade do ar, resultante de exhalações mephiticas então mais abundantes" (Correspondências com o Ministério do Império. 28 de fevereiro de 1860. Arquivo Nacional). Além desta, o remetente da referida correspondência relata que, muitas outras causas contribuem para a insalubridade na Cidade da Parahyba, as quais tem uma relação direta com a geografia do lugar, conforme pretendemos afirmar. Dentre estas são citadas "a proximidade de terrenos alagadiços cobertos de mangues á margem do Rio Parahyba na extensão de cinco legoas; outra a existência de uma alagoa e das várzeas paludosas do 'Riacho Jaguaribe' a barlavento desta cidade" (Idem). Fazia-se necessário, portanto, um controle sobre o lugar e a adequação destes espaços a fim de que os mesmos deixassem, de acordo com o saber médico da época, produzir gases nocivos à saúde dos habitantes, favorecendo à disseminação de doenças.

O Presidente da Província prossegue esta correspondência apontando outras causas para a insalubridade na Cidade da Parahyba, ao relatar que, além das causas naturais, as quais transcrevemos acima, há ainda "a ignorância e incúria da população da classe inferior, o pouco ou nenhum asseio das ruas e quintaes, onde muitas vezes se achão grandes focos de infecção" (Correspondências com o Ministério do Império. 28 de fevereiro de 1860. Arquivo Nacional). A miséria era, portanto, entendida como causa, como a culpada dos males que assolavam a cidade, visto a ignorância desta parcela da população, de acordo com o discurso dos administradores locais.

$\mathrm{Na}$ Cidade da Parahyba, no ano de 1858, o Presidente da Província em correspondência ao Ministério do Império afirma a necessidade da construção de um estabelecimento que funcionasse enquanto 'escola industrial de aplicação à agricultura'. Segundo o mesmo, com o hábito de trabalhar desde cedo, as crianças paraibanas teriam em si a produção dos melhores "effeitos em relação não só a industria do paiz como á moralidade de seus habitantes, cujas classes pobres, em falta de educação conveniente, vegetão na mizeria e contrahem vícios que a ociosidade alimenta." (Correspondência ao Ministério do Império. 11 de outubro de 1858. Arquivo Nacional).

Neste sentido, é criada a Lei Provincial n ${ }^{\circ} 24$, de 04 de julho de 1857 que autoriza a instalação de escolas agrícolas teóricas e práticas na província, com a intenção de que estas escolas fossem "uma imitação dos asylos agrícolas quaes se observão na Suissa. Nella reunirei um certo número de meninos desvalidos, sobretudo orphãos, collocando-os d'est'arte em posição de se tornarem cidadãos aproveitáveis, o que certamente não aconteceria se continuassem a viver no estado de degradação em que nacerão" (Correspondência ao Ministério do Império, 11 de outubro de 1858. Arquivo Nacional). A instalação destas escolas para as crianças e desvalidos justificava-se para que esta parcela da população pudesse "empregar no trabalho lucrativo o que hoje dispendem no jogo e em outros vícios a que recorrem como único meio de distração" (Id. Ibd.). Desta forma, seriam 
considerados homens bons e deixariam de representar perigo, posto estarem ocupados com seu trabalho, já que seriam considerados perigosos aqueles a quem a elite julgasse avesso à higienização e ao trabalho, isto é, os pobres; os doentes mentais; os doentes em geral; os ociosos, enfim, toda parcela da população que por algum motivo representasse oposição à ordem imposta e sonhada pela elite para o espaço das urbes, portanto, aqueles que fossem julgados contrários: ao progresso, ao moderno, ao higiênico e ao belo.

A questão do trabalho na cidade que se pretende moderna e higiênica sempre foi um ponto importante, o que nos leva a anotar algumas medidas que foram utilizadas pelos administradores da Cidade da Parahyba, a fim de combater a ociosidade da população durante o período analisado. Fazia-se importante dar trabalho à população pobre, não só para diminuir a quantidade de pessoas que transitavam pelas ruas 'sem rumo' e 'sem ocupação', como também, e principalmente, a fim de exercer o controle sobre esta parcela da população, considerada perigosa por não ser, segundo o discurso da elite, adeptas aos princípios reguladores do trabalho.

O trabalho era entendido como meio para sustentar a ordem social, a qual só seria atingida através de "uma nação produtiva, que reprimisse sistematicamente o não-trabalho, o ócio, a vagabundagem" (CAMPOS, 2004, p. 17), ou seja, já que o trabalho era visto como uma das principais maneiras de moralizar o ser humano cria-se na Cidade da Parahyba, a verba 'Socorros Públicos'. Essa verba tinha o intuito de que os retirantes e mendigos fossem aproveitados nos diversos serviços e equipamentos urbanos que vinham sendo implementados na cidade durante o final do século XIX e início do século XX. E neste sentido as epidemias eram consideradas avessas ao trabalho já que as mesmas ocorriam "aniquilando tantas vidas e arrancando tantos braços, tão necessarios, naquelles tempos, ao trabalho profícuo de agricultura e povoamento do solo, em uma nacionalidade de pequena população, que não podia soffrer esta guerra de extermínio" (PINTO, 1910, p. 118).

Com o propósito principal de controlar esta parcela da população considerada perigosa, bem como enquadrá-los no sistema moralizador do trabalho, a verba 'Socorros Públicos', consistia em fazer com que os indigentes e retirantes da seca fossem utilizados nas obras públicas que estavam sendo realizados na capital. Em troca receberiam auxílio ou, conforme denominado à época, 'ração', o que garantiria a sua sobrevivência.

Vários são os documentos que versam sobre este tema, como o relatório do Presidente da Província, do ano de 1878, o qual explana que

[...] no empenho, pois, de dar occupação util e proveitosa ao excessivo numero de emigrantes validos, que, dispersos, na mais completa ociosidade, percorrião em lastimável estado de fome e nudez, as ruas d'esta Capital, recommendei á mesma Commissão que os fizesse empregar em diversas obras públicas de maior urgencia. (RPP, 1878. p. 14)

A parcela da população que vagava pelas ruas sem trabalho, e que, por ser considerada um dos motivos para o contágio e transmissão de doenças, precisava ser ocupada (empregada) e, mais ainda, controlada. Esta população, em geral era proveniente do interior da Província, e vinha à capital paraibana, principalmente nos períodos em que suas cidades estavam sendo acometidas pela seca, em busca de melhores condições de vida, e somava-se aos indigentes da própria cidade aumentando ainda mais o espetáculo de miséria observada nas suas ruas. Conforme nos conta o Presidente da Província em seu relatório do ano de 1879, “esta corrente de pessoas desvalidas que descem de vários pontos do interior para esta cidade, pouco tem diminuído, e ninguém ignora quaes as necessidades que passam essas famílias desvalidas atravez desses caminhos, ingerindo fructos e raízes bravias, águas insalubres e carregando, á pé, creanças sob o calor ardente da secca" (RPP, 1879, p. 12). Neste mesmo relato, o Presidente da Província acrescenta em relação à saúde desta parcela da população que, 
Vê-se, pois, que essa aglomeração do povo que aqui existe já com a saúde mais ou menos deteriorada, fora de seus hábitos, sem agasalho, sem commodos, sem alimentação regular, sem roupas, será ainda a causa do desenvolvimento de molestias, até que seja retirada completamente do seio desta cidade essa população adverticia e ociosa, proporcionando-se-lhe meios de trabalho na factura de estradas e do plantio á que deverão entregar em nucleos coloniaes. Não há duvida que é dessa aglomeração de indivíduos indigentes, dessa promiscuidade de sexos e falta absoluta de asseio, que resulta o mephetismo, que determina no organismo uma verdadeira germinação deletéria. (RPP, 1879, p. 12).

Portanto, seriam perigosos, à medida que eram considerados responsáveis pela transmissão dos seus males à população em geral, e, sobretudo, à elite. Esta última residia nas principais ruas da cidade, em habitações luxuosas e em ruas urbanizadas, geralmente mais dotadas de infraestrutura do que as ruas mais distantes da área central. Área esta que concentrava ainda as igrejas e os prédios da administração pública, ou seja, onde acontecia a vida urbana. No entanto, esta população abastada tinha à sua vista diariamente o espetáculo da pobreza e da indigência que lhes incomodava, pois este era o lugar escolhido pelos pobres para transitarem e deixar à mostra seus males e sua miséria, em busca de se enquadrar em algumas das obras organizadas pelas mulheres vinculadas às instituições de caridade, tal como ocorria com a Santa Casa de Misericórdia.

Neste sentido, na Cidade da Parahyba "outro fator que agredia o olfato e as vistas da emergente elite comercial urbana dizia respeito ao fato das secas tangerem para a capital os sertanejos e, com eles, todo um cortejo de miséria, imundície e peste" (SÁ, 1999, p. 65). Em períodos de seca, a cidade recebia uma grande leva de retirantes, a qual sem infraestrutura para recebê-los, tinha o seu cotidiano ainda mais afetado, posto que, com o acréscimo populacional as epidemias assolavam e dizimavam um número maior de habitantes, bem como o contágio se dava com mais força. Estes retirantes da seca faziam parte da população considerada perigosa, pois através deles o perigo de contaminação e a falta de trabalho poderia influenciar a 'boa gente'.

Além do hábito de utilizar a população retirante na realização de obras públicas, em 1867, o Chefe de Polícia Dr. Antonio Joaquim Buarque de Nazareth "ordenava que os presos codemnados á galés fizessem a limpeza das ruas da cidade e pequenos trabalhos de nivelamento e terraplanagem." (MEDEIROS, 1913, p. 121). Esta prática tornou-se comum até o ano de 1889, momento em que, graças 'ao espírito de modernidade', e "sob o pretexto de que o espetáculo de presos encalcetados asseiando a rua era deprimente, findou-se o uso estabelecido pelo Chefe de Policia de 1867." (Idem).

A ideia de segregação daqueles considerados perigosos permanece e leva à criação de estabelecimentos nos quais a observação desta parcela da população por parte dos "homens bons" e da elite deveria ser evitada. Neste sentido, são criados os asilos de mendicidade e asilos de loucos na Cidade da Parahyba. Para tratarmos desta questão, partiremos principalmente dos relatórios da Santa Casa da Misericórdia. Com base nestes documentos, observamos que no final do século XIX, há uma solicitação para a construção do 'Asilo de Mendicidade', o qual ainda não havia sido construído em detrimento do desejo dos administradores locais, e mais particularmente do Provedor da Santa Casa de Misericórdia, que assina o referido relatório.

Graças à inexistência de tal asilo, a medida tomada era a de distribuir o di $\neg$ nheiro de esmolas a todos os pobres que vagavam pelas ruas da cidade, mas principalmente àqueles que por ventura estivessem prestando algum serviço, seja diretamente à Santa Casa de Misericórdia, ou mais especificamente à municipalidade. Esta afirmação pode ser exemplificada ao observamos o relato, publicado no ano de 1889, no qual o Provedor da Santa Casa afirma que no momento em que tomou posse

[...] um homem, que, posto não estivesse curado de sua vizivel enfermi $\neg$ dade, que parece difficil de completa cura. Pedio, e ob $\neg$ teve alta. Passados alguns mezes voltou em pior estado, e foi segunda vez admittido no hospital, d'onde sahindo em Maio, ou principio de Junho ultimo, tornou a entrar. Elle que não achava fora meios de subsistência, e que não podia expor-se á serviços pezados, quiz servir voluntaria-mente no hospital, dando-se-lhe a ração de doente. (RSCM, 1889, p. 15) 
Ressalta-se assim a importância do trabalho e de fazer com que a população de um modo geral, mas principalmente a "classe perigosa" não se encontrasse ociosa, como medida de segurança e de controle. Neste mesmo ano, a quantidade de indigentes na Cidade da Parahyba sofre um acentuado acréscimo, visto que o interior da Província estava passando por um período de seca. Este fato faz com que seja "tal a concurrencia de retirados do interior da Província, famintos, maltrapilhos e doentes á procura de asylo e recursos, que em pouco tempo chegou a 170 o numero d'esses infelizes, de ambos os sexos e de todas as edades, recolhidos, alimentados e tratados no Hospital." (Id. Ibd. p. 16). Salientamos que o autor refere-se ao Hospital da Santa Casa de Misericórdia, já que era inexistente na cidade um asilo de mendicidade. No ano de 1911, o estabelecimento do asilo, continuava a "ser uma aspiração", segundo relato do Provedor da Santa Casa de Misericórdia "o estado de desenvolvimento da nossa capital não supporta mais o espectaculo deprimente da mendicidade nas ruas e nas praças" (RSCM, 1911, p. 17). Por conta da inexistência do dito asilo e com receio de que houvesse entre estes indigentes a propagação e o contágio de alguma doença epidêmica e, ainda pior, que estes transmitissem seus males à população da cidade, foi criado, em 1912, pelo Presidente da Província, um outro hospital, para onde muitos destes retirantes fo $\neg$ ram transferidos, denominado de "Cruz do Peixe", por situar-se no sítio de mesmo nome.

A idéia exposta acima e que vai permear o isolamento daqueles considerados indigentes e, portanto, perigosos no que concerne à manutenção da higiene da cidade, vem a promover também o isolamento dos considerados loucos, e por isso, não menos perigosos. No entanto, mesmo no início do século XX, qual seja, no ano de 1906, eram inúmeras as reclamações quanto a este estabelecimento. O relatório do Provedor da Santa Casa de Misericórdia, para este ano afirma que

[...] este estabelecimento onde são recolhidos os infelizes que perdem a rasão, não corresponde, de modo algum, aos intuitos da caridade e nem ás prescripções da sciencia medica. E' antes uma prisão, e esta bem martyrisante, do que um manicomio, com o necessário conforto e os meios hygyenicos indispensáveis á vida humana, infelismente os recursos financeiros da Misericordia ainda não são sufficientes para comportarem as despesas com os diversos ramos de serviço, a cargo da nossa administração, deixando saldo que possa ser applicado na construcção de um edifício moderno embora de pequenas proporções, mas que seja um azylo completo e onde os alienados recebam um tratamento compatível com os preceitos da medicina e encontrem bálsamo ás suas dores. (RSCM, 1906, p. 14/15)

Sobre a miséria entendida enquanto reduto de enfermidades, Urteaga (1980) propõe que, junto às doutrinas miasmáticas havia também a identificação, principalmente por parte dos médicos de que, a 'culpa' da existência de epidemias na cidade seria daquela população de menor poder aquisitivo, o que leva a ocorrência da eugenia, ou do preconceito social. Neste período, os médicos atribuíram à pobreza, às más condições de alimentação e de habitação, ao excesso de horas de trabalho, ao adensamento dos bairros industriais, bem como, à falta de infraestrutura e de equipamentos urbanos como os responsáveis pela transmissão e contágio de doenças. Com base nestas evidências, é que, principalmente partir do século XIX, os médicos e engenheiros, e aqueles responsáveis pela administração das cidades vão ser incumbidos de levantar os lugares considerados problemas para a construção de habitações e edificação em geral, ou ainda serão eles os responsáveis pela escolha dos lugares para construção dos cemitérios, matadouros, hospitais, lazaretos, enfim, todas as construções consideradas perigosas em relação à transmissão de doenças, por favorecer, segundo o discurso médico da época, a disseminação de doenças. Cabia ainda a estes profissionais 'esconder' dos olhos da elite a mendicância, a ociosidade, e a doença. Momento em que os hospitais, mais que lugares para tratamento de saúde, representam asilos em que esta população que não têm 'capacidade' de cuidar de si e da sua saúde é enviada para que viva à custa da caridade e da igreja.

No início do século XX, questiona-se "si o saneamento da nossa capital pode soffrer mais adiamentos, já com uma população" aproximada de 25 mil habitantes. (MARÓJA, 1913, p. 435). Muitas serão as transformações e construções que se darão nas primeiras décadas deste século, como 
por exemplo, a iluminação pública que é instalada no ano de 1910 e o serviço de abastecimento de água, sobre o qual falaremos adiante, inaugurado no ano de 1912. É neste mesmo ano ainda, mais precisamente em 14 de agosto do referido ano, que é inaugurado um Asilo de Mendicidade na cidade, aos cuidados do senhor Joaquim Manoel Carneiro da Cunha, o Barão de Abiahy. A instalação do dito asilo teve como intuito deixar a "cidade expurgada de verdadeiros e pseudo-mendigos" (CUNHA, 1968 , p. 27), consequentemente, torná-la mais bela a medida que esta parcela da população era segregada e isolada neste estabelecimento.

Este asilo, portanto, cumpre a sua dupla função, a primeira delas era a de auxiliar os desvalidos que transitavam pelas ruas da cidade e que necessitavam de auxílio financeiro a fim de garantir o seu sustento e sobrevivência, mas, sobretudo, cumpre a função de retirar das ruas da cidade moderna e civilizada parcela da população que não deveria ser vista, nem percebida pela elite, já que o simples fato de aí estarem, nas ruas centrais da cidade, representaria atraso e regresso. Portanto, o Estado, que deveria agir como regulador e propor uma educação sanitária e uma melhoria na qualidade de vida, através, por exemplo, da instalação de equipamentos urbanos responsáveis por diminuir a ocorrência de epidemias, atua, na prática, através da segregação e do isolamento desta parcela da população que se vê obrigada a sair da mira disciplinadora a fim de poder realizar suas atividades longe do policiamento e da regulação.

A perseguição aos pobres e às suas práticas causadoras de doenças permanece fortalecida pela crença na Teoria dos Miasmas, a qual continua sendo a mais aceita entre a comunidade médica. Entretanto, com o passar dos anos e o aumento das técnicas possíveis para a investigação em laboratório, as teorias médicas passam a ser reformuladas. Diniz (1999) ao analisar o conceito de epidemia, propõe que

[...] o discurso médico a respeito da propagação das epidemias vai deixando de lado os imprecisos sentidos do olfato e tato para afirmar-se no sentido da visão. O nascimento da clínica no final do século XVIII que se estrutura através de uma linguagem que fala do olhar, inaugura um novo discurso, marcado pela objetividade, formalidade, empiricidade, concretude, análise e profundidade. (DINIZ, 1999, p. 190)

A objetividade aí contida seria, portanto, a responsável por criar as condições para uma experiência clínica, passando da análise dos sentidos sobre o olfato e o tato, tal como ocorriam para as Teorias do Contágio e dos Miasmas, para o sentido da visão, a partir dos estudos biológicos, dando lugar a uma nova teoria: a da Transmissão. Teoria esta que contribui com o surgimento da medicina moderna. No entanto, o embate entre os que acreditavam na Teoria dos Miasmas e aqueles que divulgavam as novas teorias ligadas à transmissão de doenças não seria resolvido rapidamente, a divulgação destas novas descobertas apesar de ter, prontamente suscitado debates científicos entre a comunidade médica, muitos anos foram necessários até que as mesmas fossem aceitas e passassem a ser utilizadas no tratamento urbano e médico. Neste sentido, mesmo nas primeiras décadas do século XX, muitas cidades continuam tendo seus regulamentos e ordenações baseadas e justificadas pelo discurso higiênico pautado ainda na Teoria dos Miasmas.

No Brasil, vários são os registros e obras bibliográficas que retratam como as cidades são modificadas a partir do ideário que permeava o Movimento Higienista e que, por sua vez, propõe uma forma específica de pensar e gerir o espaço urbano.

A análise documental utilizada ao longo deste trabalho nos leva a considerar que o Movimento Higienista, sobretudo durante os séculos XIX e primeiras décadas do século XX favoreceu uma alteração no espaço urbano das cidades em geral. E, por conseguinte, também provocou alterações na área urbanizada da Cidade da Parahyba. Cidade essa que, embora apresentasse uma dinâmica de menor intensidade do que outros centros urbanos do mesmo período tem na imagem destes grandes centros, sobretudo na das grandes cidade brasileiras como o Rio de Janeiro, por exemplo, ou nas cidades européias, um modelo. Uma representação do que deveria ser entendido enquanto progresso. Em vista disso, era essa imagem de progresso e de Modernidade que os administradores 
locais juntamente com a elite, desejavam para a Cidade da Parahyba. O progresso e a Modernidade que, por sua vez, encontravam-se diretamente ligados à promoção da higiene e da saúde pública.

Esses temas, portanto, se fazem importantes para a análise de qualquer cidade durante o período citado, qual seja, entre meados do século XIX e início do século XX, pois, em decorrência das epidemias que as assolavam tornava-se necessário não só evitar o contágio como também prevenir a ocorrência das mesmas. Sendo um tema recorrente no que diz respeito à análise urbana para este período.

Como podemos perceber a partir das fontes analisadas e da bibliografia consultada, em virtude da ausência de conhecimento médico acerca do contágio e transmissão de doenças que atacavam e dizimavam os habitantes da cidade, a higiene era entendida com o único meio de evitar que estes problemas fossem gerados e, principalmente disseminados pela população urbana. Esse fato ocorria porque, seria a falta de higiene, tanto nos espaços físicos da cidade, a partir dos considerados 'focos de insalubridade', como da população, a partir dos maus hábitos, que as epidemias, tais como a febre amarela, a varíola e a cólera, sendo estas as doenças que mais atacavam a população, que se daria a origem e a transmissão de doenças.

\section{CONSIDERAÇÕES FINAIS}

A partir da análise realizada dos documentos oficiais e não oficiais, tais como as posturas, decretos e determinações em geral que eram produzidos na Cidade da Parahyba, ou no nível da nação e que, por sua vez, deveriam ser também aqui observadas; nas matérias jornalísticas e ainda nas obras bibliográficas produzidas à época podemos averiguar de que forma a cidade supracitada teve o seu espaço adequado e/ou modificado a partir dos preceitos higiênicos, sob a ordem de sanear, higienizar e embelezar que se faziam constante nos discursos da elite, daqueles que participavam da administração da cidade; ou ainda nas determinações, leis e decretos que eram difundidos à época.

Os desejos de progresso e higiene, aliados à intenção por tornar essa cidade moderna, sob os moldes dos grandes centros urbanos, faz com que, conforme observamos ao longo dos capítulos deste trabalho, a cidade tenha seu espaço modificado, através da abertura de novas ruas; alargamento das ruas já existentes; construção de casas de saúde ou do isolamento para aqueles que seriam considerados um risco no que concerne à transmissão de doenças. Citamos ainda a instalação de alguns equipamentos urbanos, como o cemitério e o abastecimento de água, entre outras medidas, são exemplos destas modificações.

No entanto, fica claro que estas modificações não se dão apenas no espaço físico da cidade e, por sua vez, promovem modificações também nos hábitos e costumes da população aí residente, em virtude das solicitações que dizem respeito diretamente ao cotidiano, como a proibição por banhar-se nas fontes, fato bastante corriqueiro entre a população de menor poder aquisitivo; a localização de determinados estabelecimentos destinados a venda de gêneros alimentícios; o próprio enterramento nos cemitérios e conseqüente proibição de manter as igrejas enquanto redutos dos mortos. Todas estas medidas provocam alterações na forma de habitar e pertencer à cidade.

Vale considerar ainda que as alterações na cidade, sobretudo a implementação das melhorias sanitárias e de infraestrutura na cidade que se dão baseadas no discurso higiênico, na maioria das vezes não ocorre de maneira igualitária, como exemplo citamos o próprio abastecimento de água, que, ao ser executado limita-se às ruas mais centrais da cidade, nas quais habitava a população de maior poder aquisitivo. Contudo, mesmo com estas limitações, pode-se observar transformações em toda a cidade, e para todos os seus habitantes, pois mesmo aqueles que não tem o espaço físico em que habitam alterado, tem no controle higiênico, nas determinações e normas, ou mesmo na ocorrência de doenças um contato direto, como este que denominamos Movimento Higienista. Movimento Higienista por promover sim uma mudança, nos espaços, nos hábitos, nos costumes, e, sobretudo, na forma de habitar e pertencer à cidade. 


\section{REFERÊNCIA BIBLIOGRÁFICA}

ANDRADE. Rita de Cássia Gregório de. As ruas da Cidade Baixa: Cotidiano e Espacialidade: A Rua Beaurepaire Rohan. Relatório final de pesquisa PIBIC-UFPB (Programa de Bolsas de Iniciação Científica) João Pessoa, 2005.

BENÉVOLO. Leonardo. História da Arquitetura Moderna. São Paulo: Perspectiva, 1994.

BOARINI. Maria Lúcia (org.) Higiene e raça como projetos: Higienismo e Eugenismo no Brasil. Maringá: EDUEM, 2003.

CAMPOS, Paulo Fernando de Souza. Os enfermos da Razão: Cidade planejada, exclusão e doença mental (Maringá, 1960-1980). São Paulo: Annablume, 2004.

DINIZ. Ariosvaldo da Silva. Epidemia: História Epistemológica e cultural de um conceito. Revista Política e Trabalho n. ${ }^{\circ}$ 15. Setembro, 1999.

JARDIM. Vicente Gomes. Monografia da Cidade da Parahyba. Revista do Instituto Histórico e Geográfico da Paraíba. Vol. 02. 1910

MAIA. Doralice Sátyro. As intervenções urbanísticas e as transformações das ruas da cidade da Parahyba. Anais do Simpósio Nacional de História. João Pessoa. Julho de 2003 (cd rom)

MAIA. Doralice Sátyro. A Legislação brasileira e o tratamento da cidade e da vida urbana no período imperial (1822-1850). Anais do X Seminário de História da Cidade e do Urbanismo. Recife. 2008.

MARÓJA. Flávio. A Nossa Hygiene: Considerações Gerais. Revista do Instituto Histórico e geográfico da Paraíba. N. ${ }^{\circ}$ 03. 1911.

MEDEIROS. Coriolano de. Subsídios para a história da hygiene pública na Parahyba. Revista do Instituto Histórico e Geográfico da Paraíba. N. ${ }^{\circ}$ 03. 1913.

OLIVEIRA. Octavio G. de. Referencias a remotas epidemias de cóleras no Norte e no Nordeste do Brasil.

Revista do Instituto Histórico e Geográfico da Paraíba. n. ${ }^{\circ} 18.1958$

PINTO. Irineu. O Cholera Morbus na Parahyba. Revista do Instituto Histórico e Geográfico da Paraíba. n. ${ }^{\circ} 02.1910$

RAMALHO. José. Pequenas Achêgas para a crônica da cidade. Revista do Instituto Histórico e Geográfico da Paraíba. N. ${ }^{\circ} 13.1958$.

SÁ. Lenilde Duarte de. Parahyba: Uma cidade entre miasmas e micróbios. O serviço de Higiene Pública, 1895 a 1918. (Tese de doutorado) Ribeirão Preto, 1999.

SALES. Andréa L. Porto e MAIA. Doralice Sátyro. Cidade da Parahyba: Transformações no uso das ruas (século XVIII a 1889). Revista Cadernos do LOGEPA - Série Texto Didático Ano 02, Número 4 - Jul/ Dez de 2003

URTEAGA. Luis. Miseria, miasmas y microbios. Las topografías médicas y el estudio del médio ambiente en el siglo XIX. Revista Geo Crítica. Septiembre 1980.

Trabalho enviado em maio de 2012

Trabalho aceito em junho de 2012 